\title{
APPLICATION OF HYBRID IC'S TO THE AUTOMOTIVE ELECTRONICS MARKET IN EUROPE
}

\author{
ECKART VON RODA
}

Robert Bosch GmbH, 7000 Stuttgart 30, Federal Republic of Germany

\begin{abstract}
In the last few years hybrids have been increasingly used in automotive electronics in Europe. With examples from the $\mathrm{BOSCH}$ and BLAUPUNKT production range their application in regulators, breakerless ignition modules, electronically-controlled fuel injection systems and car radios is illustrated. The elements and techniques used to assemble the hybrids, and the advantages which can be gained are discussed.
\end{abstract}

\section{INTRODUCTION}

The application of electronics, and especially microelectronics in motor vehicles, has the aim of increasing service value, ease of operation and safety, of lessening the environmental impact of the vehicle and reducing the energy consumption, especially in operation. This last point is especially topical at this time.

Apart from the car radio, this development began in Europe in about 1967 when electronically-controlled fuel injection developed by $\mathrm{BOSCH}$ and transistorized ignition were first employed for engine control. ${ }^{1}$ Thanks to their advantages in terms of low maintenance requirements, improved driving comfort, increased fuel economy and reduced pollutant concentration in the exhaust gas, such systems have since gained extensive shares of the market.

With the growing number of units produced, with increasing complexity of systems being allowed up the same or even less space and under the market pressure to cut system costs, increasing numbers of thick film-circuits and -hybrids have been used in the last few years.

This development will be illustrated by examples of hybrids in BOSCH and BLAUPUNKT products.

\section{HYBRIDS IN MOTOR VEHICLES}

\subsection{Hybrid Regulators}

As early as with the introduction of the electronic attached-type regulator marketed by BOSCH in 1968, thick film ciruits - though still purely resistance networks - secured a firm place in automotive electronics and even at this time enabled cost-saving matching of functions (Figure 1).

In 1978 a hybrid regulator was introduced (Figure 2). It is mounted in a hermetically-sealed metal housing approximately corresponding to TO 3 and consists only of a small thick film board with a few conductors, 2 resistors and one IC, of a quench diode and of a

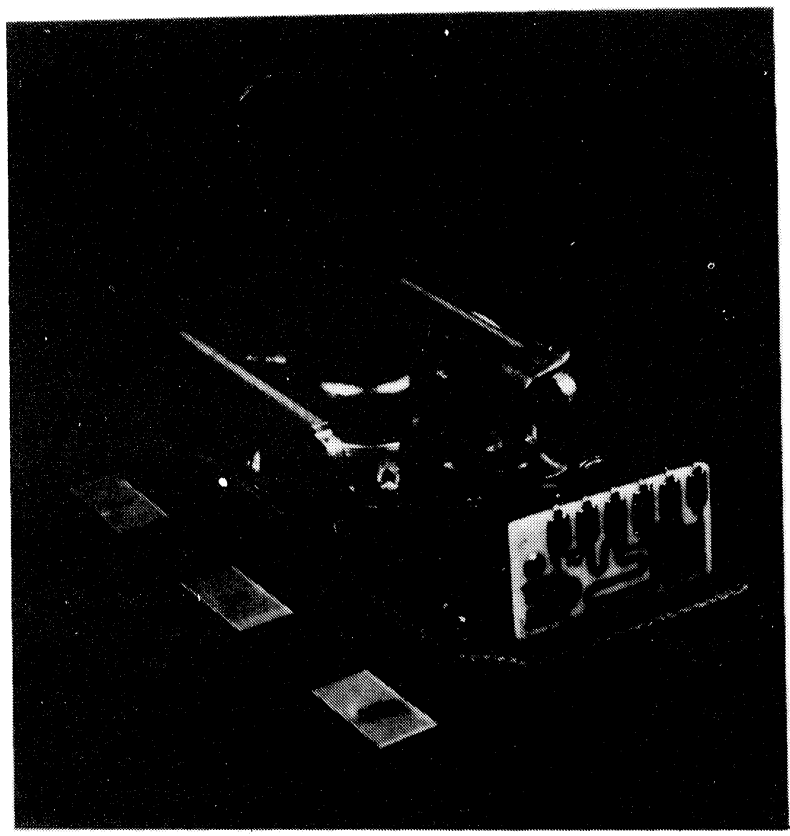

FIGURE 1 BOSCH 'discrete" regulator with thick film resistor network. 


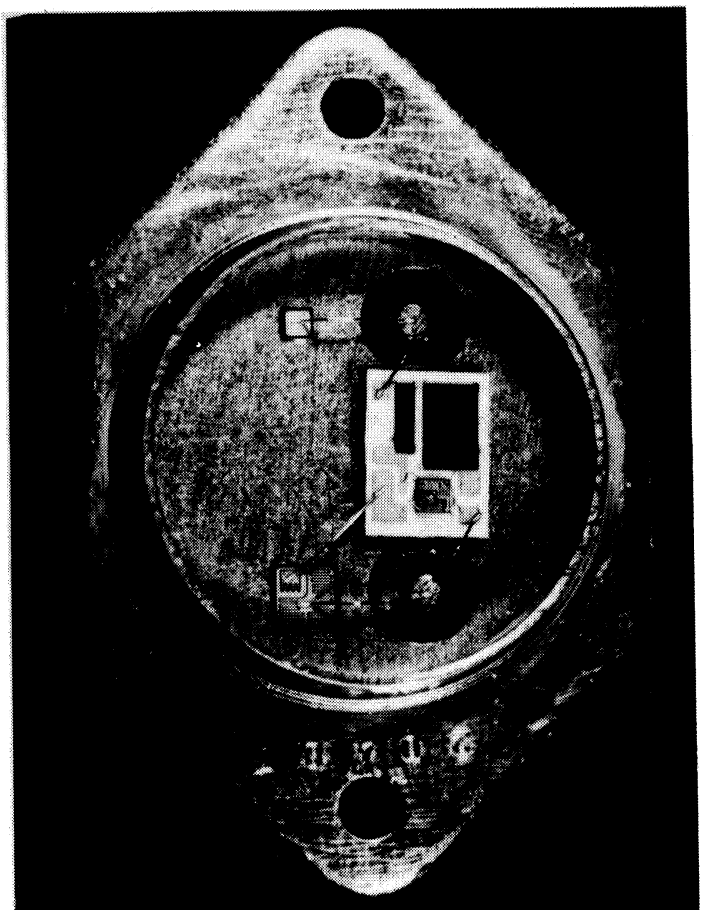

FIGURE 2 BOSCH hybrid regulator.

Darlington output stage, soldered directly to the housing bast.

The semiconductors are bonded using aluminium wire, the wire thickness being $50 \mu \mathrm{m}$ for the IC and $200 \mu \mathrm{m}$ for the remaining contacts.

\subsection{Hybrid Control Units for Transistorized Ignition}

The development of breakerless ignition systems began in Europe initially with the aim of providing sufficient ignition voltage for special high speed engines. At first they were used rarely.

In the USA, however, due to emission-control legislation, a more dynamic development took place from 1970 onwards. By 1975 all manufacturers had fully transferred to the more effective transistorized ignition system.

Exports to the USA, the development of new engines and soaring petrol prices led to increased interest in this type of ignition system in Europe as well ${ }^{2}$ (Figure 3).

In $1978 \mathrm{BOSCH}$ introduced the first hybrid ignition modules on the market, for both the induction-type pulse generator and the Hall-type pulse generator (Figures 4,5 ). These were substantially miniaturized as compared to the discrete unit. In contrast to the regulator, a "semihermetic" solution with silicone

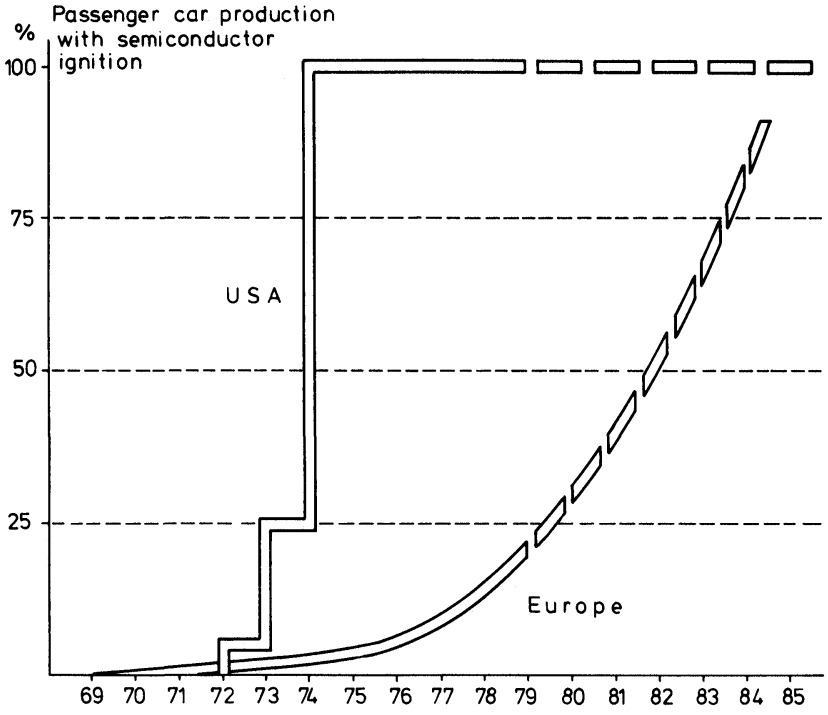

FIGURE 3 Semiconductor ignition: Introduction USA/Europe.

encapsulant in a plastic housing was selected in order to satisfy the various demands of the automotive industry regarding housing and plug geometry while maintaining robust design. The hybrid is cemented to the base with epoxy, the Darlington final stage soldered. The IC contacts and the connections from the hybrid to the plug tabs are bonded with aluminium wire or resistance welded with nickel wire, conductive adhesive being used for the capacitors. Additional mechanical protection

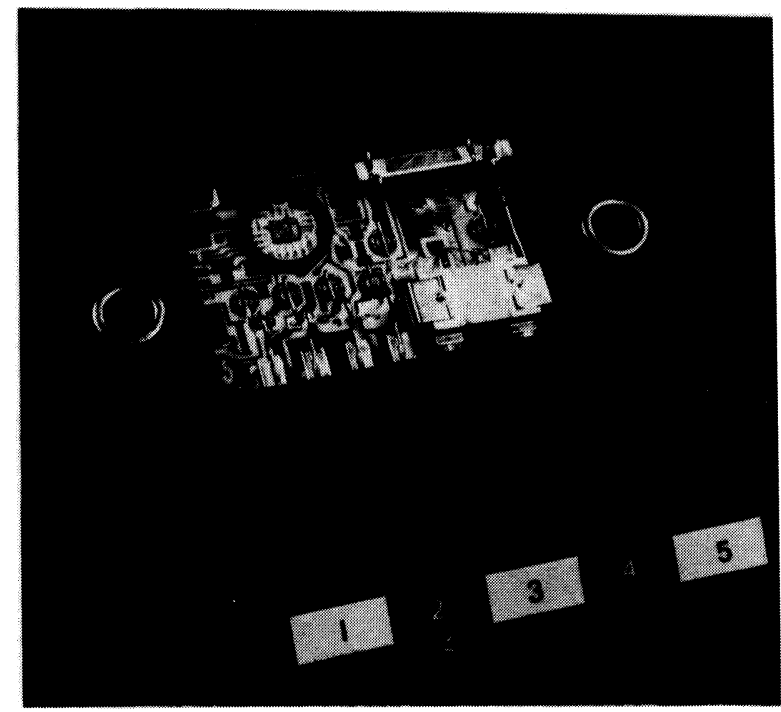

FIGURE 4 BOSCH hybrid transistorized ignition for induction-type pulse generator. 


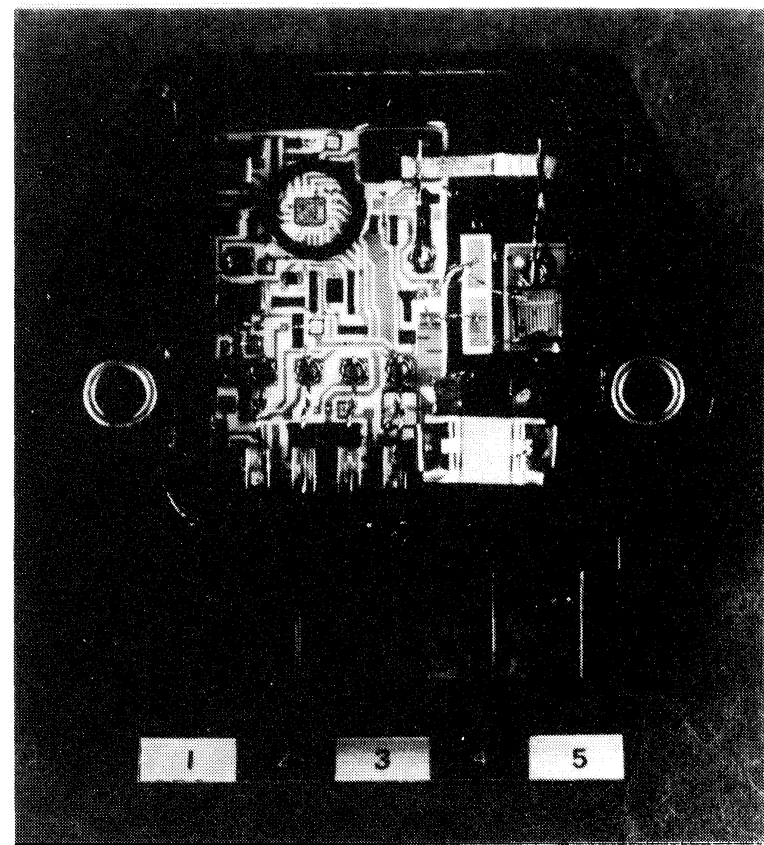

FIGURE 5 BOSCH hybrid transistorized ignition for Hall type pulse generator.

of the IC is provided by a plastic ring fixed by adhesive and filled with silicone rubber encapsulant.

In $1980 \mathrm{BOSCH}$ will introduce a still smaller control unit of soldered-design using flip chip ICs. Figure 6 shows prototypes, on the right with the capacitor removed.

Further miniaturization of control units is not foreseen, because plug and heat sink (Figure 7) are already size-determining factors and moreover with the advance of fully electronic coil ignition, additional functions must be accommodated in the control unit.

It is expected that in a few years time the European market will have largely changed over to hybrid ignition modules.

\subsection{Hybrids for Fuel Injection}

Fuel injection can no longer be dispensed with in modern automobile construction. ${ }^{3}$

Whereas at first it was the higher attainable maximum power which recommended this kind of fuel induction, today it is above all the lower fuel consumption and lower exhaust emissions which contribute to the more widespread use of fuel injection.

The control units of today's injection systems (electronically controlled "L-Jetronic" with and

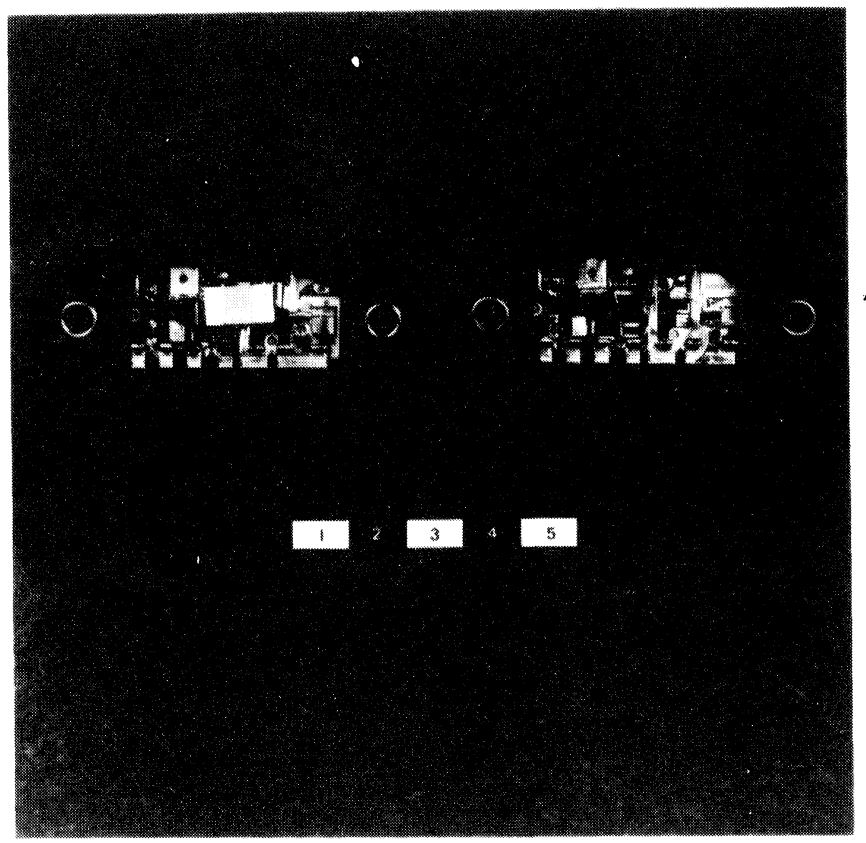

FIGURE 6 BOSCH hybrid transistorized ignition in soldered version

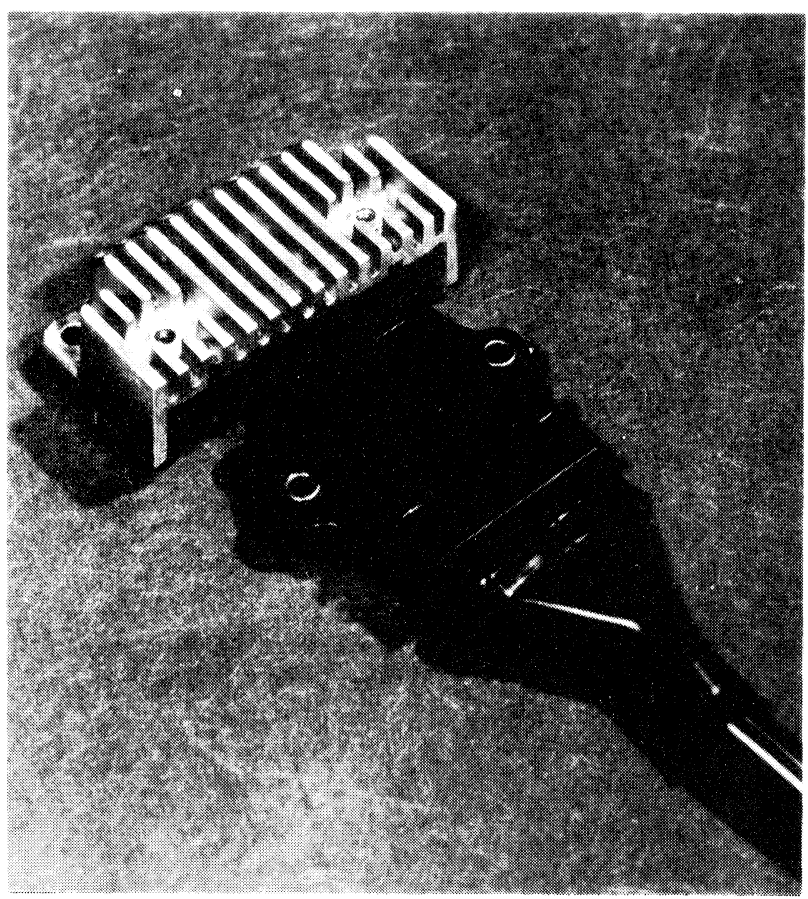

FIGURE 7 BOSCH hybrid transistorized ignition with plug and heat sink. 
without $\lambda^{\dagger}$-closed-loop control, mechanically controlled "K-Jetronic" with electronic $\lambda$-closed-loop control) are built up using printed circuit methods.

The block diagram (Figure 8 ) shows the functional scope - taking the "L-Jetronic" as an example.

In order to satisfy the requirements of the market for a multitude of various systems on one hand,

- every manufacturer makes other demands,

- every engine type requires an individual solution

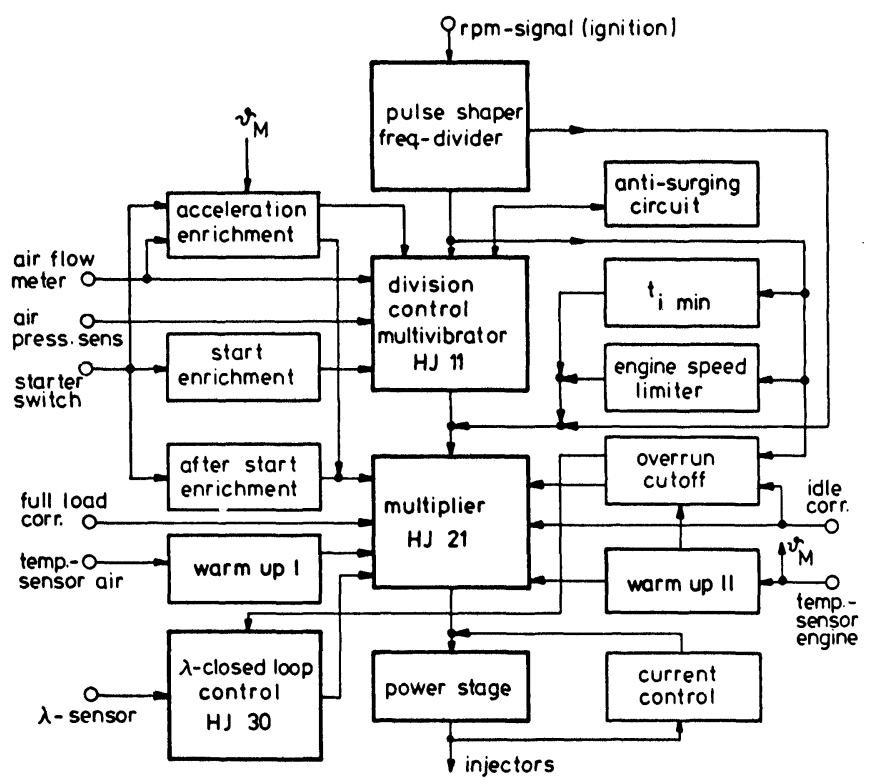

FIGURE 8 L-Jetronic control unit. Block diagram.

and the demands of the automotive manufacturers for an ever increasing number of functions in the same or smaller volume on the other hand, from the beginning of 1978 a number of important functions have been compressed into 3 hybrids.

The hybrids are designed such that adaptation to the various engine types can be performed, computer-controlled with a laser, within the scope of function matching in the final stage of hybrid manufacture. The hybrid for the $\lambda$-closed-loop control is used both in the "L-Jetronic" and "K-Jetronic" with principally the same design.

In this way it was possible to run 19 "L-Jetronic" control units and 10 control units required for the "K-Jetronic" with $\lambda$-closed-loop control alone with these 3 basic hybrids.

$\dagger \lambda=$ air/fuel ratio
The hybrids used - thick film technique, unpacked IC, bonded with $50 \mu \mathrm{m}$ aluminium wire and sealed with silicone rubber - are shown in the following figures:

Figure 9 shows the control multivibrator with anti-surging circuit

Figure 10 the multiplier stage with warm-up regulator and

Figure 11 the hybrid for the $\lambda$-closed-loop control

Figure 12 shows as an example the relative size of the hybrid and the replaced discrete circuit.

Figure 13 compares typical control units of the "L-Jetronic" with $\lambda$-closed-looped control

Figure 14 control units of the "K-Jetronic" with $\lambda$-closed-loop control, in each case before and after introduction of the described hybrids. Further integration is planned.

\subsection{Hybrids in Air-mass-sensors}

An important element of modern injection systems is a component for measuring the intake air flow or still better the mass flow. ${ }^{4}$ This has the task of supplying the electronic control unit with a voltage signal as a function of air quantity or mass.

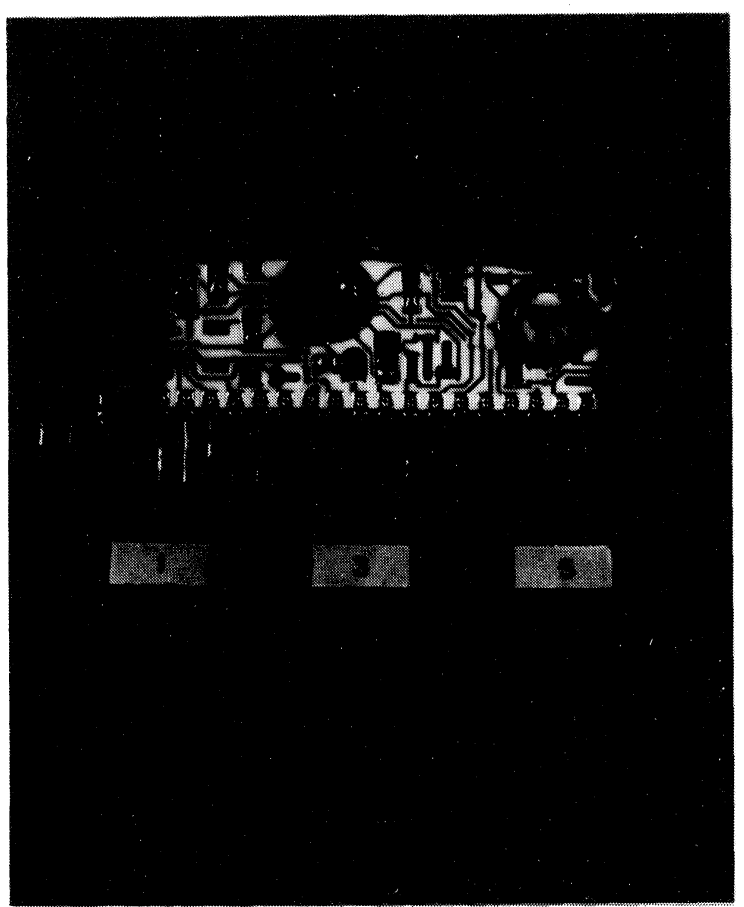

FIGURE 9 BOSCH Jetronic hybrid HJ 11. 


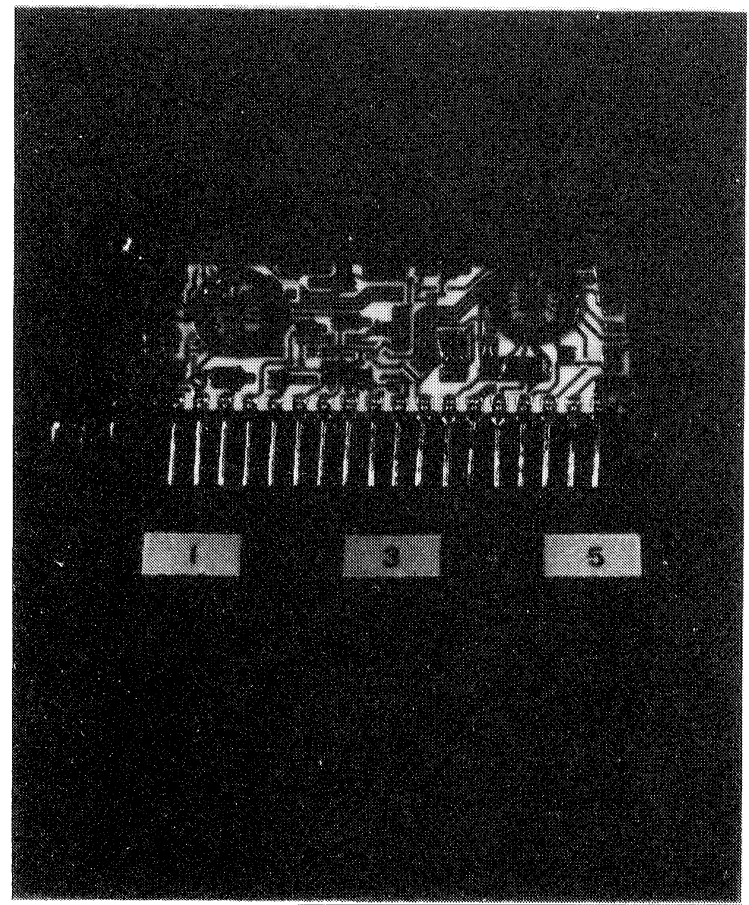

FIGURE 10 BOSCH Jetronic hybrid HJ 21.

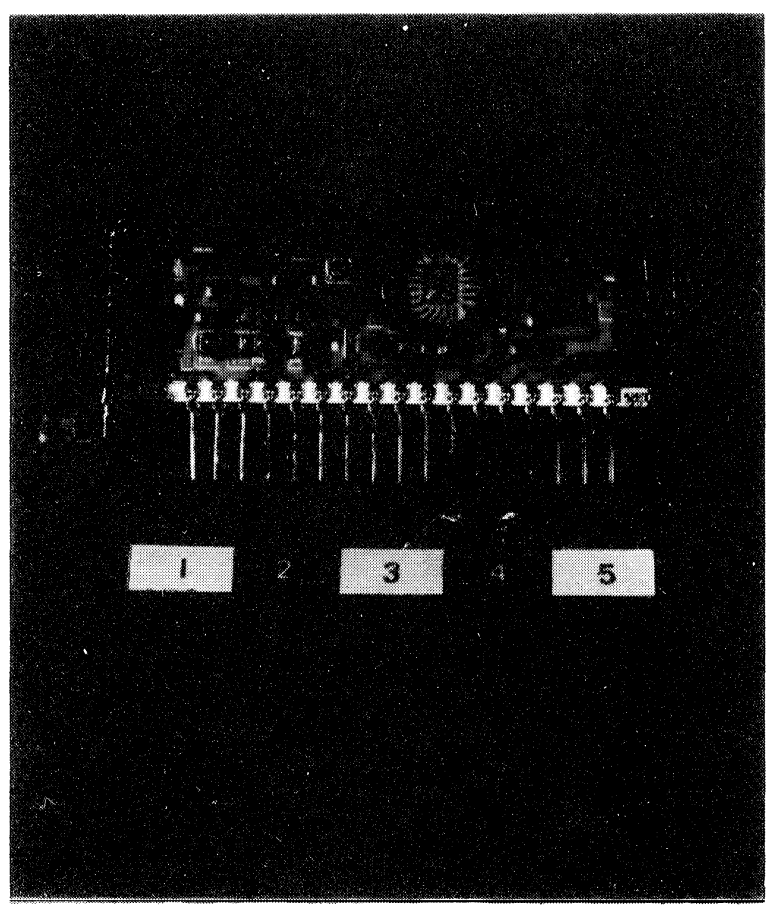

FIGURE 11 BOSCH Jetronic hybrid HJ 30.

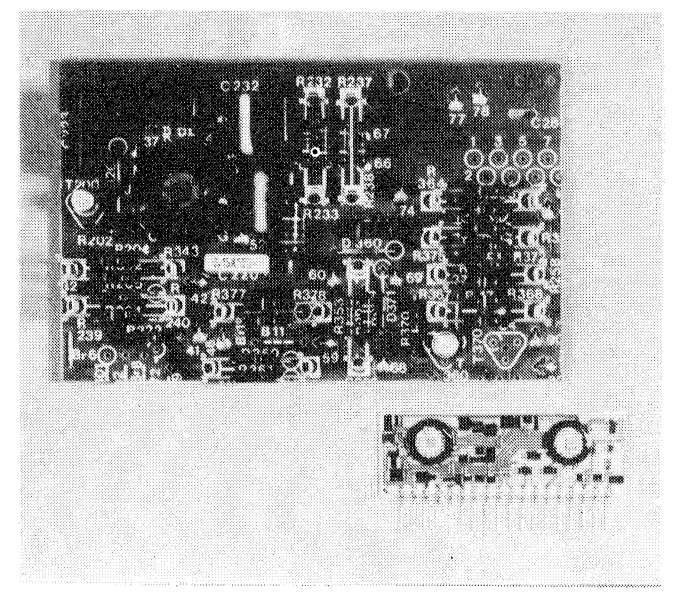

FIGURE 12 BOSCH Jetronic hybrid HJ 21: Size comparison with discrete circuit.

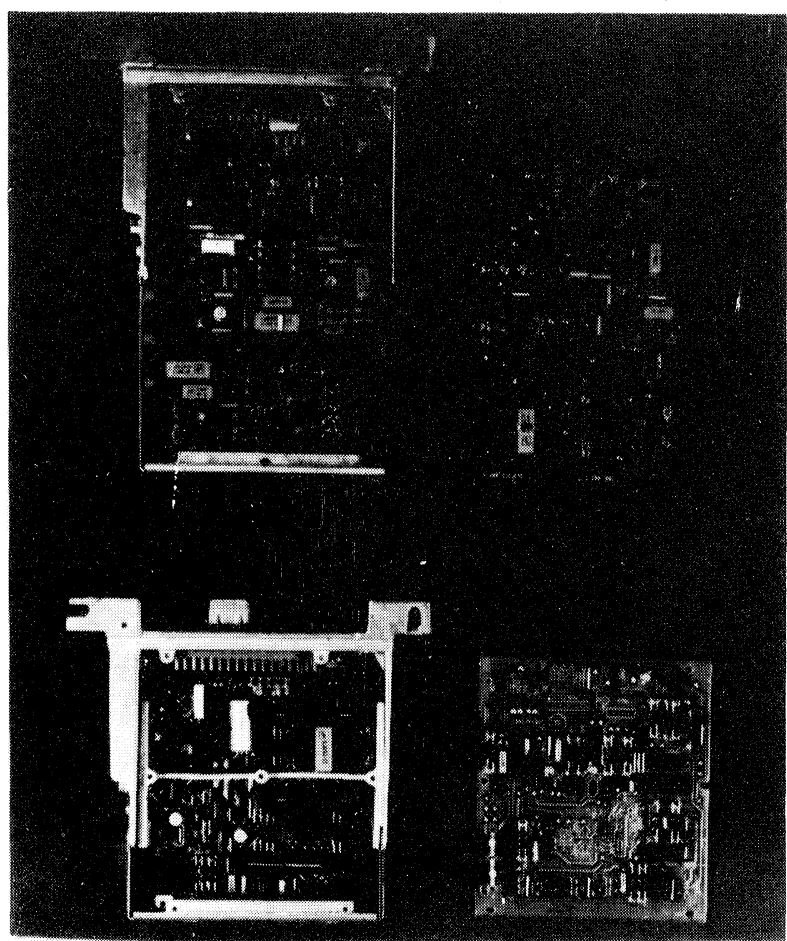

FIGURE 13 L-Jetronic: Size comparison of control unit with/without hybrids.

In $1973 \mathrm{BOSCH}$ began series production of air-flow-meters. These air-flow sensor-flap measuring devices merely require a passive thick-film circuit essentially a conductive plastic linear potentiometer on which a sliding contact, permanently attached to the 


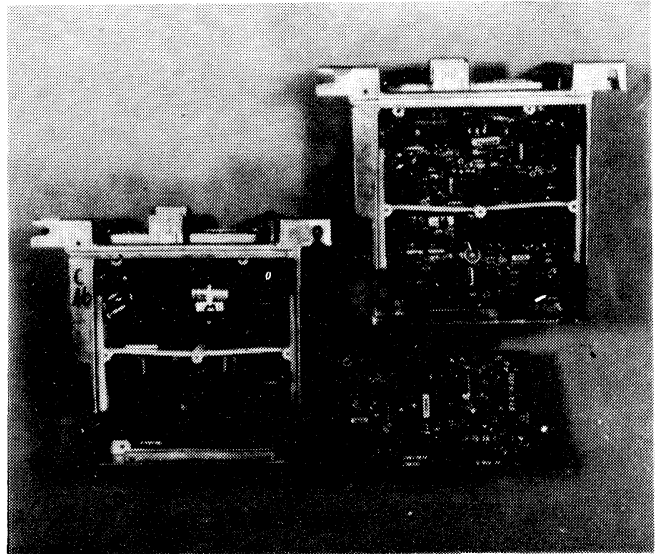

FIGURE 14 BOSCH $\lambda$-closed-loop control for K-Jetronic: Size comparison of control unit with/without hybrid.

sensor flap, can move backwards and forwards (Figure 15). Matching to the appropriate engine type is performed by laser trimming of parallel low-impedance cermet ladder attenuator resistors.

However air flow measurement has the disadvantage that the air density is included in the measurement, so that under certain circumstances pressure effects have to be corrected. This disadvantage is avoided in the

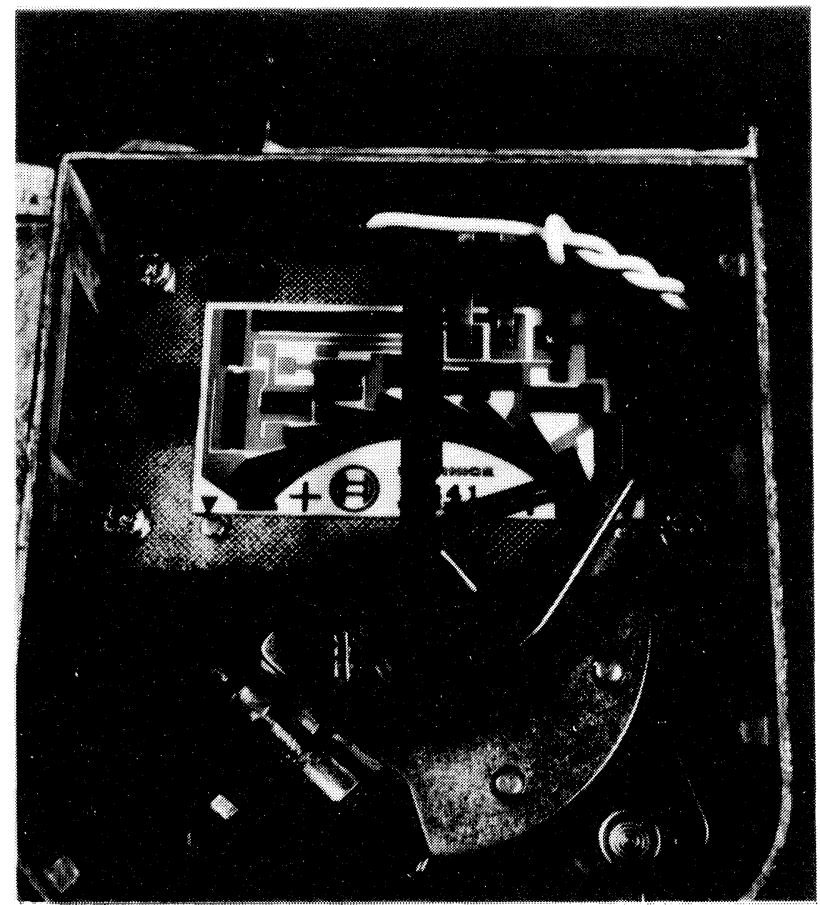

FIGURE 15 BOSCH air-flow-sensor with thick film potentiometer. hot-wire mass-air flow meter newly developed by BOSCH. ${ }^{5}$

In this device, a platinum wire in a bridge circuit, which is located in the intake air flow is heated to a constant temperature; the necessary heating currents give an indication of the flowing air mass. The tubular metering channel with the hot wire can be seen in Figure 16; the attached chamber contains, in the form of a hybrid circuit, the evaluation logic circuit.

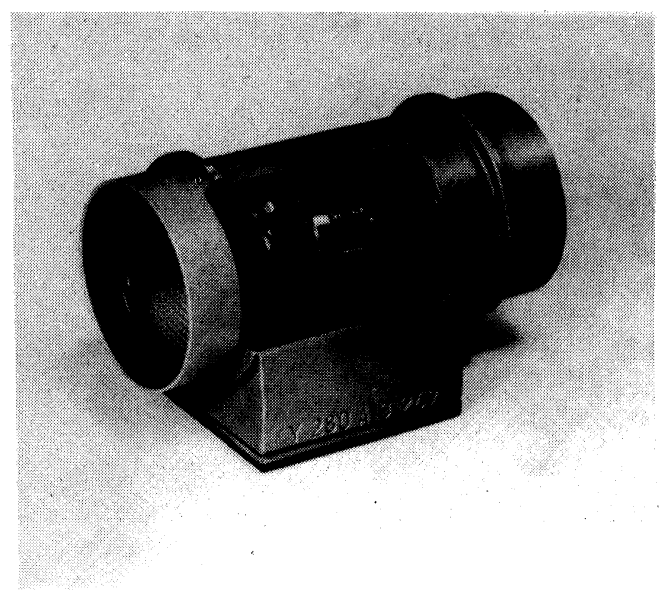

FIGURE 16 BOSCH hot wire air-mass-flow meter.

\subsection{Hybrids in car radios}

The volume required for the installation of a car radio has been drastically reduced in the last 50 years (Figure 17) and today has settled down to a volume of approx. 1 litre. Parallel to this trend, however, the demands on the car radio have substantially increased:

\section{Station selection buttons for AM and FM}

Tape-cassette recorder, also in stereo

Traffic-state transmission decoder based on the "ARI system", in the development of which BLAUPUNKT was decisively involved ${ }^{6}$

all had to be accommodated in this volume.

To this end hybrid technology, which has been systematically used by BLAUPUNKT since 1977 . made a substantial contribution. The following figure (Figure 18) shows a block diagram of a typical car radio. Circuits with high power dissipation, with many coils and capacitors, as well as with frequencies $>10 \mathrm{MHz}$ have not been hybridized up to now. Dependent upon type, up to 8 hybrids can be used in a car radio. 


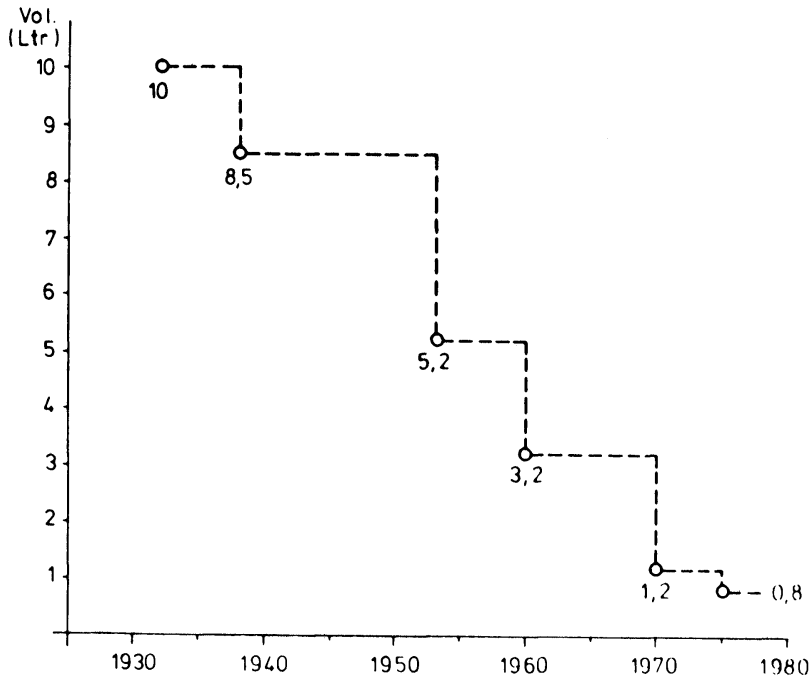

FIGURE 17 Reduction of car radio volume 1932-1980.

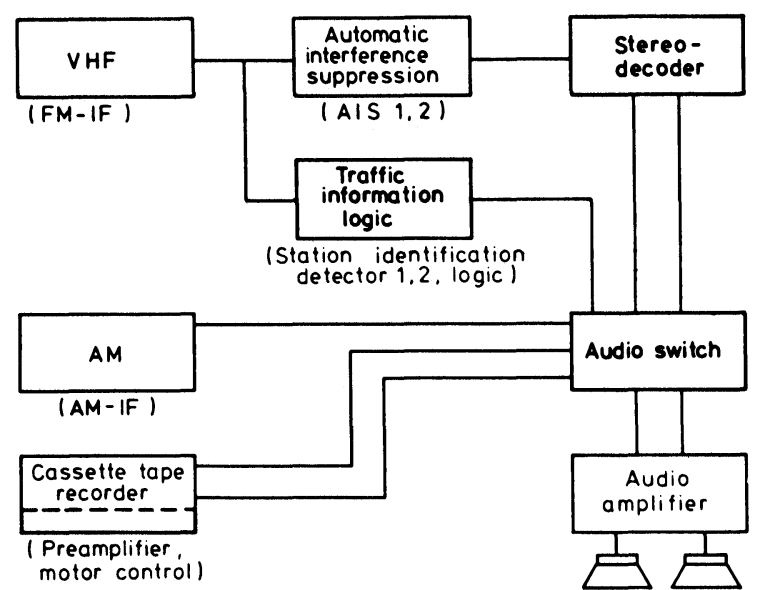

FIGURE 18 Block diagram of BLAUPUNKT car radio.

The following figures show typical hybrids.

Figure $19 \mathrm{FM}$ intermediate frequency

Figure 20 Automatic interference suppression

Figure 21 Traffic-state transmission logic

Figure 22 Station identification detector and

Figure 23 Tape recorder preamplifier.

It can be seen that two basically different hybrid families are concerned:

On one hand hybrids with unpacked, gold

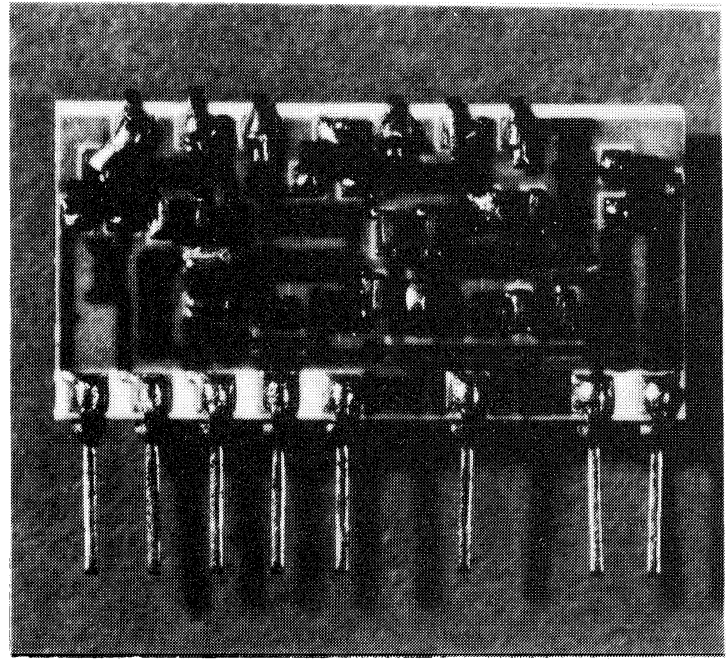

FIGURE 19 Hybrids in BLAUPUNKT car radios: FM-IF

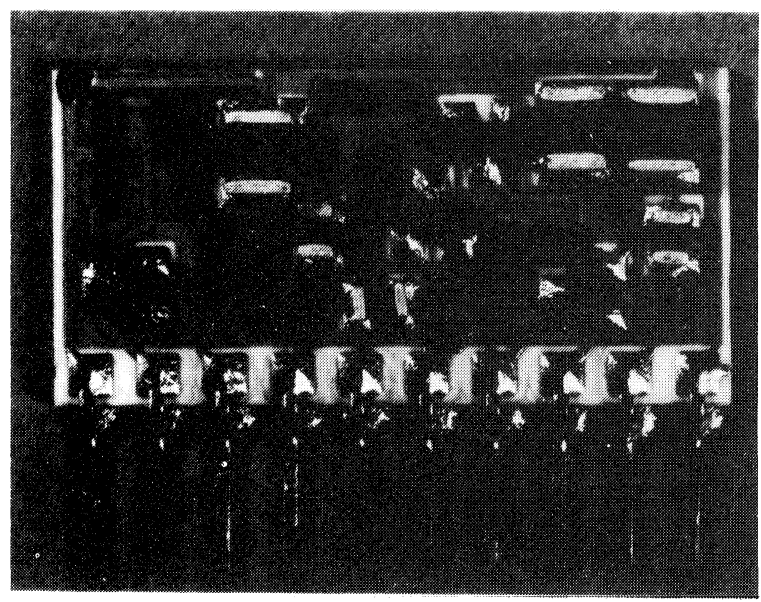

FIGURE 20 Hybrids in BLAUPUNKT car radios:

Automatic interference suppression.

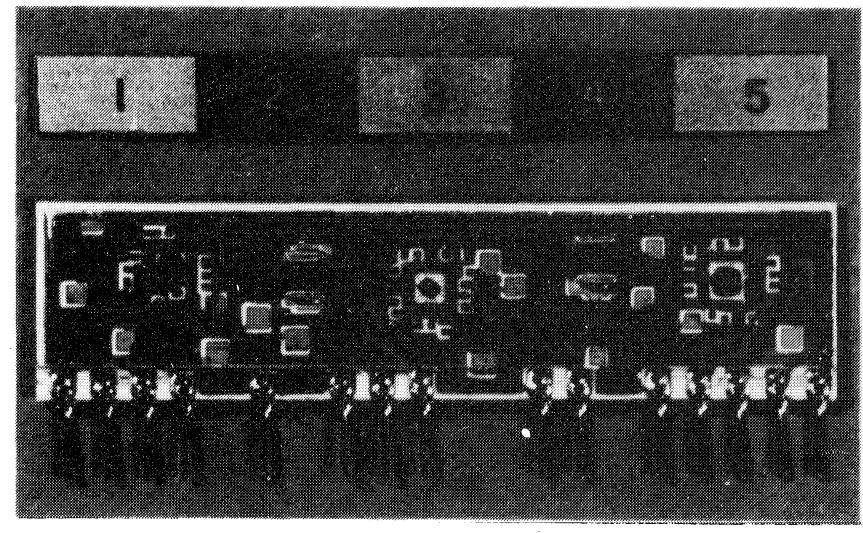

FIGURE 21 Hybrids in BLAUPUNKT car radios: Traffic information logic. 


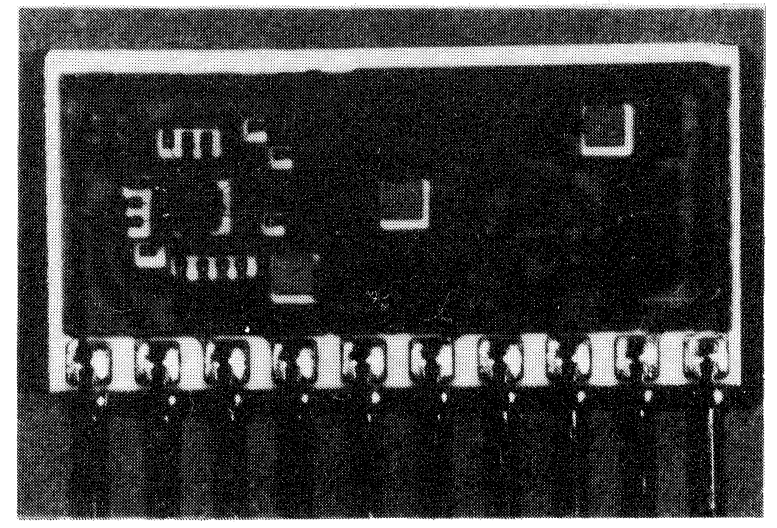

FIGURE 22 Hybrids in BLAUPUNKT car radios: Station identification detector.

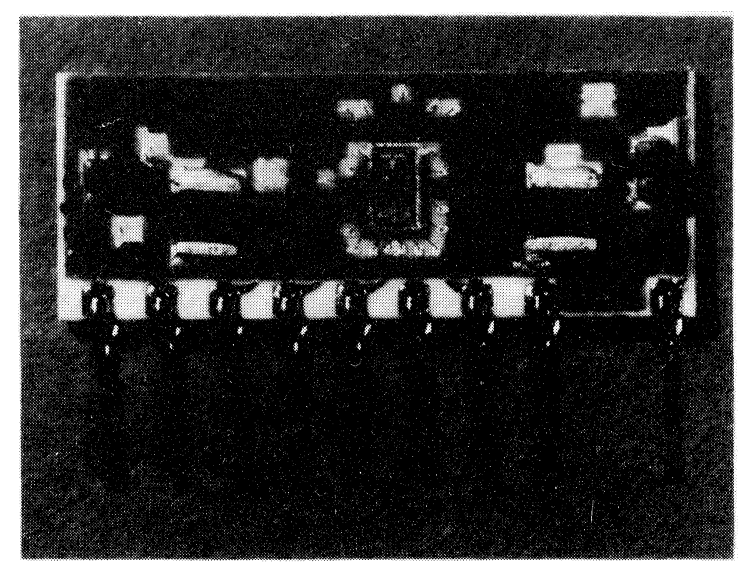

FIGURE 23 Hybrids in BLAUPUNKT car radios: Tape recorder preamplifier.

wire-bonded ICs and glued chip capacitors. The ICs are protected after bonding against environmental influences by a soft or semi-hard silicon rubber drop. This technique is used especially when LSI-ICs are available for which testing in the wafer provides satisfactorily reliable information about operation.

On the other hand, exclusively soldered hybrids with chip capacitors and packed individual semiconductors (Minimold, SOT 23... ). This technique is preferred in those cases where testing of the ICs in the wafer does not provide infallible information about operation.

In both cases $\mathrm{Al}_{2} \mathrm{O}_{3}$-ceramic is used as substrate with thick-film conductors and resistors.

\section{HYBRID TECHNOLOGY}

The examples presented show that even within one company, different paths may be chosen for the design of hybrids and hybrid devices depending upon application and other conditions. The principal differences lie in the housing or packing of the hybrids and in the selection of components for the hybrid design and the contacting methods which result from this.

The differences are small in the area of design of passive circuits. Thick film methods are used as standard with $\mathrm{Al}_{2} \mathrm{O}_{3}$-ceramic as substrate. Conductors - usually $300 \mu \mathrm{m}$ wide and approximately $10 \mu \mathrm{m}$ thick - are printed using palladium-silver paste or in the case of soldered hybrids using platinum-silver paste; bonding pads for wire-bonded IC contacts are additionally coated with gold paste. Resistors are printed using ruthenium dioxide paste.

Then the circuit is covered with protective glass, whereby in some cases recesses are provided for the resistors. The terminal strips are automatically attached and soldered after assembly of the hybrids. Substantial differences are apparent in the type of components used and the resulting joining methods.

At a company such as BLAUPUNKT for example, who buy in all of their components, the selection of the "best" technology depends substantially upon the availability of the necessary elements on the market Two technologies have proved themselves to be usable and viable:

On one hand complete soldering for ready-packed semiconductors and capacitors, and

On the other hand, automatic thermosonic wire bonding using $25 \mu \mathrm{m}$ gold wire for unpacked ICs in wafers; capacitors are joined by adhesives in this method of construction.

The use of flip chips has been excluded up to now because of the restricted availability of these modules on the market.

BOSCH has so far made standard use of unpacked ICs, which are contacted by ultrasonic bonding with aluminium wire of $50 \mu \mathrm{m}$ diameter. This method fulfills all requirements for use in motor vehicles; it especially ensures low material costs and high reliability, high current-carrying capacity up to $2 \mathrm{~A}$ and good cooling of the ICs via the die bond. In addition - especially important in the initial phase - flexibility with regard to various production figures and IC geometries was also provided. Since ultrasonic aluminium wire bonding is substantially independent of the type of base material used, it can also be used on normal printed circuit 


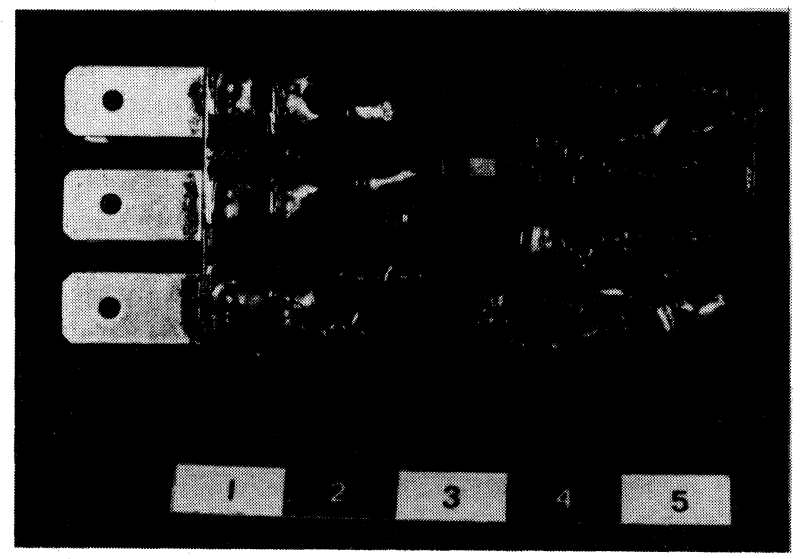

FIGURE 24 BOSCH hazard warning flasher.

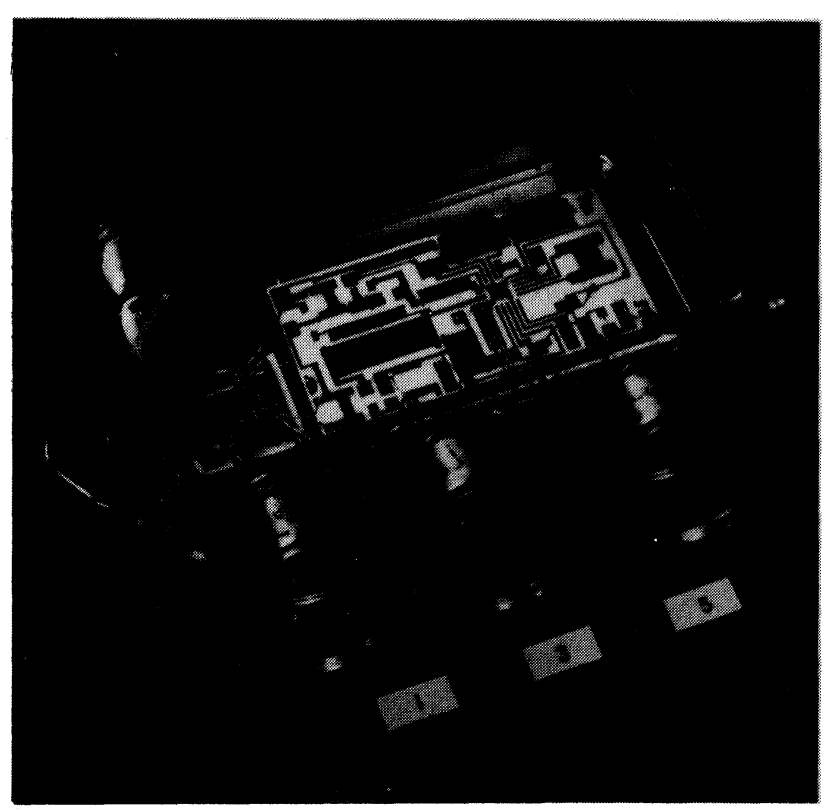

FIGURE 25 Hybrid transistorized ignition: "Hermetic" laboratory prototype.

boards such as this mass produced hazard warning flasher (Figure 24).

With increasing production figures, however, it will now be economically of interest to change this concept for several hybrids: Thus ignition modules - as already mentioned - will be fully soldered using flip chip ICs from 1980 onwards.

Plastic housing with metal base plates and silicone rubber sealing of the circuit are largely used in the design of units. Hermetic constructions, as in the case of the $\mathrm{BOSCH}$ hybrid regulator, are the exception.
Investigations by $\mathrm{BOSCH}$ into the possibility of introducing a hermetic metal housing for the hybrid ignition system for example, stopped still at the laboratory stage (Figure 25). The multitude of housing shapes and terminal geometries for robust plugs required by the market could not be realized using economic methods.

For hybrid modules to be used in printed circuit boards, at least the unpacked ICs, but frequently the entire circuit are sealed with silicone rubber encapsulant and mechanically secured by a plastic or ceramic cap. At BOSCH, ICs inserted unpacked in the hybrid are additionally protected by a plastic ring which is glued on and sealed with gel. Work is proceeding on a replacement for this method by sealing with a resin which has sufficient mechanical stability.

\section{CONCLUSIONS AND FUTURE TRENDS}

Thanks to a series of striking advantages hybrid technology has captured a firm position in European automotive electronics. Hybrids continue integration where monolithic integration is at present inadequate for reasons of flexibility, circuit design or too small output or dissipation powers. The principal advantages of hybrid technology are:

The volume and space savings which can be attained. For complete units with a considerable volume occupied by plug and heat sink the factor 2 to 3 is usually achieved, in the case of flat modules considerably more. Without the use of hybrids, in many cases the functional scope demanded by today's market can no longer be reconciled with the permissible volume.

The possibility of computer-controlled function matching of the individual hybrid or the complete unit. This allows the demands on accuracy for the individual components to be greatly reduced in some cases and what proves to be special advantage for automotive electronics - matching to various automobile or engine types can be realized starting from a basic unit.

The substantially higher flexibility as opposed to monolithic integratrion in the case of circuit modifications.

The possibility - a prerequisite being sufficient production figures - of keeping manufacturing costs low by computer-aided generation of the layout and by computer-aided automatic assembly.

The high reliability produced by the smaller number of connections. Thus, e.g. for car radios, the number of 
failures during the guarantee period could be substantially reduced by use of hybrid methods.

The high heat-carrying capacity provided by the substrate material and construction.

A few problems of hybrid technology, however, should not be forgotten:

Thus the availability and cost of modules suitable for hybrids on the market are completely unsatisfactory.

Minimold and SOT modules and especially chip capacitors, are still substantially too expensive for mass applications.

ICs suitable for wire bonding are still far from being available in sufficient quantities.

The flip chip ICs of interest for numerous applications are virtually unavailable on the market.

In addition the current price explosion for gold and silver is leading to serious increases in the cost of noble-metal-containing pastes used to date in hybrid manufacture.

Despite this, we believe that the significance of the advantages mentioned will also be decisive in the future and will ensure further advances of hybrid technology.

With the increasing number of applications in mass production, the price and availability of components suitable for hybrids will also hopefully normalize; the development of noble metal-free pastes will no doubt be considerably promoted by the current trends on the gold and silver market.

With the advance of microprocessors in automotive electronics, the elaboration of low-cost, mass production methods for the hybrid integration even of computer circuits and the development of suitable components represent the principal tasks for future advances in hybrid technology.

\section{REFERENCES}

1. H. Scholl, "Elektronische Benzineinspritzung gesteuert durch Saugrohrdruck und Drehzahl”, $A T Z, 70$, Nr. 4, pp. 115-121 (1968).

2. H. Decker, "Allumage Transistorisé, Allumage tout Electronique", Ingénieurs de L'Automobile 10-78, pp. 557-564.

3. O. Glöckler und B. Kraus, "L-Jetronic - Elektronische Benzineinspritzung mit Luftmengenmessung", Bosch Techn. Berichte, 5, pp. 7-18 (1975) 1 .

4. R. Sauer, "Der Luftmengenmesser der L-Jetronic", Bosch Techn. Berichte, 5, pp. 159-165 (1975) 3.

5. R. Sauer, "International Symposium on Automotive Technology \& Automation with particular reference to microprocessor applications", Volume 1, Sept. 78

6. P. Brägas, "Verkehrsrundfunk", Bosch Techn. Berichte, 4, pp. $179-189$ (1973) 5 . 

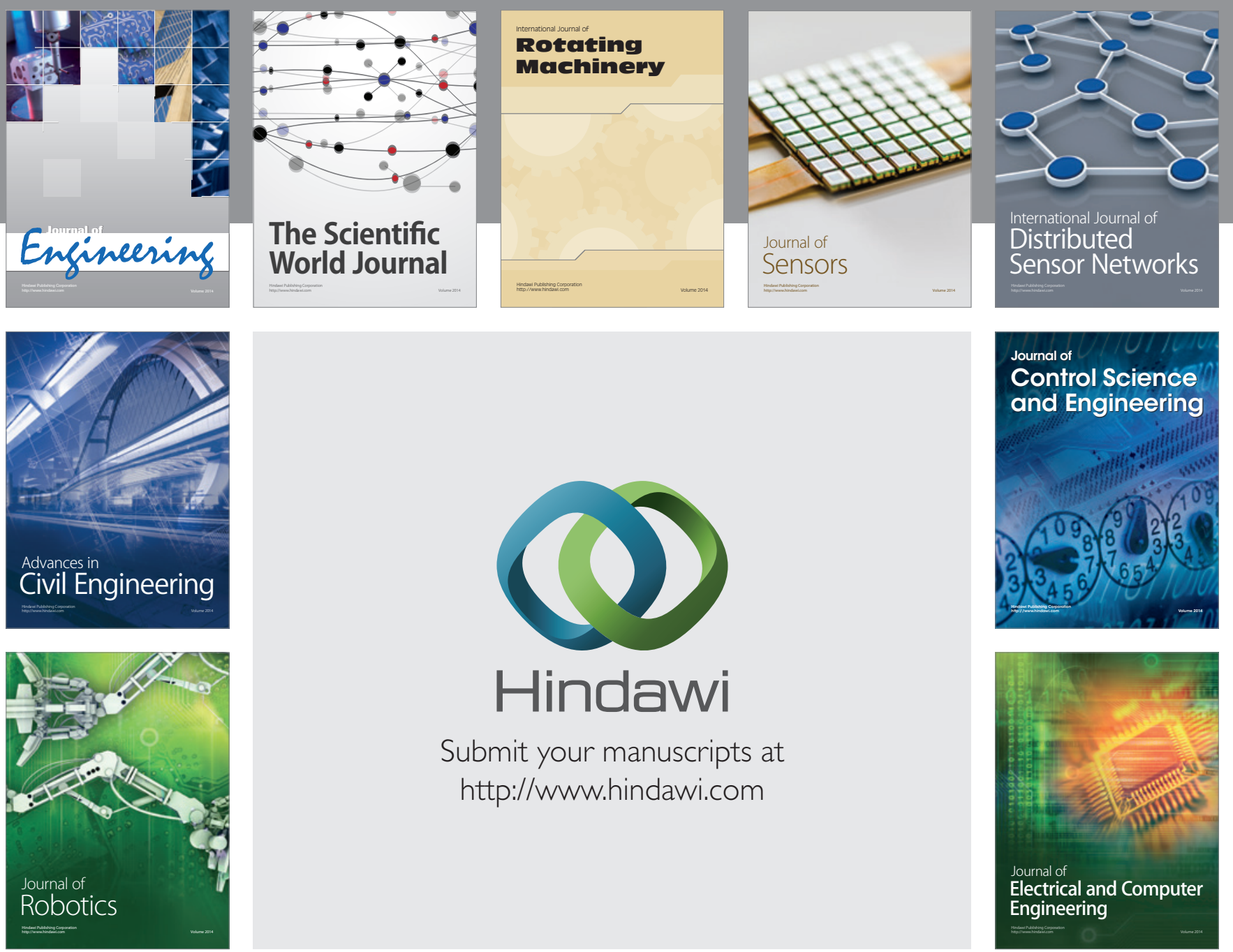

Submit your manuscripts at

http://www.hindawi.com
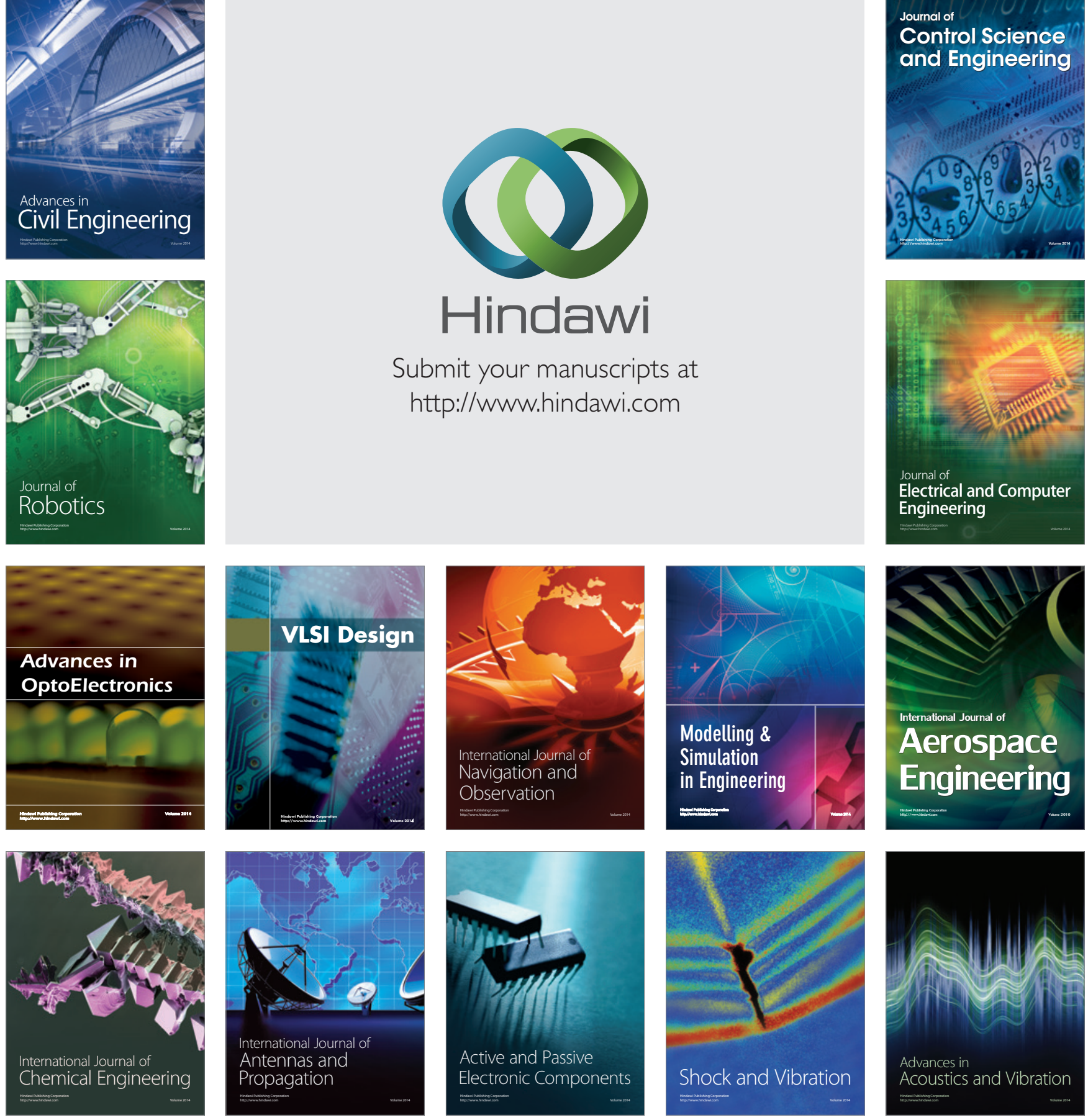